\title{
Correction to: Respiratory Rate Estimation by Using ECG, Impedance, and Motion Sensing in Smart Clothing
}

\author{
Chien-Lung Shen ${ }^{1,2} \cdot$ Tzu-Hao Huang $^{2} \cdot$ Po-Chun $\mathrm{Hsu}^{2} \cdot$ Ya-Chi Ko ${ }^{2} \cdot$ Fen-Ling Chen ${ }^{2} \cdot$ Wei-Chun Wang ${ }^{2} \cdot$ Tsair Kao $^{1}$. \\ Chia-Tai Chan ${ }^{1}$
}

Published online: 23 July 2018

(c) The Author(s) 2018, Corrected Publication August 2018

\section{Correction to: J Med Biol Eng (2017) 37:826-842 https://doi.org/10.1007/s40846-017-0247-z}

The article "Respiratory Rate Estimation by Using ECG, Impedance, and Motion Sensing in Smart Clothing", written by Chien-Lung Shen, Tzu-Hao Huang, Po-Chun Hsu, Ya-Chi Ko, Fen-Ling Chen, Wei-Chun Wang, Tsair Kao, Chia-Tai Chan was originally published electronically on the publisher's internet portal (currently SpringerLink) on 1 July 2017 without open access.

After publication in volume [37], issue [6], page [826-842] the authors decided to opt for Open Choice and to make the article an open access publication. Therefore, the copyright of the article has been changed to ()$^{\circ}$ The Author(s) 2018 and the article is forthwith distributed under the terms of the Creative Commons Attribution 4.0 International License (http://creativecommons.org/licenses/by/4.0/), which permits use, duplication, adaptation, distribution and reproduction in any medium or format, as long as you give appropriate credit to the original author(s) and the source, provide a link to the Creative Commons license, and indicate if changes were made.

Open Access This article is distributed under the terms of the Creative Commons Attribution 4.0 International License (http://creativeco mmons.org/licenses/by/4.0/), which permits unrestricted use, distribution, and reproduction in any medium, provided you give appropriate credit to the original author(s) and the source, provide a link to the Creative Commons license, and indicate if changes were made.
The original article can be found online at https://doi.org/10.1007/ s40846-017-0247-z.

Tsair Kao

tskao@ sunrise.hk.edu.tw

Chia-Tai Chan

ctchan@ym.edu.tw

1 Department of Biomedical Engineering, National YangMing University, No.155, Sec.2, Linong Street, Taipei 112, Taiwan, ROC

2 Taiwan Textile Research Institute, No.6, Chengtian Rd., Tucheng Dist., New Taipei City 23674, Taiwan, ROC 